
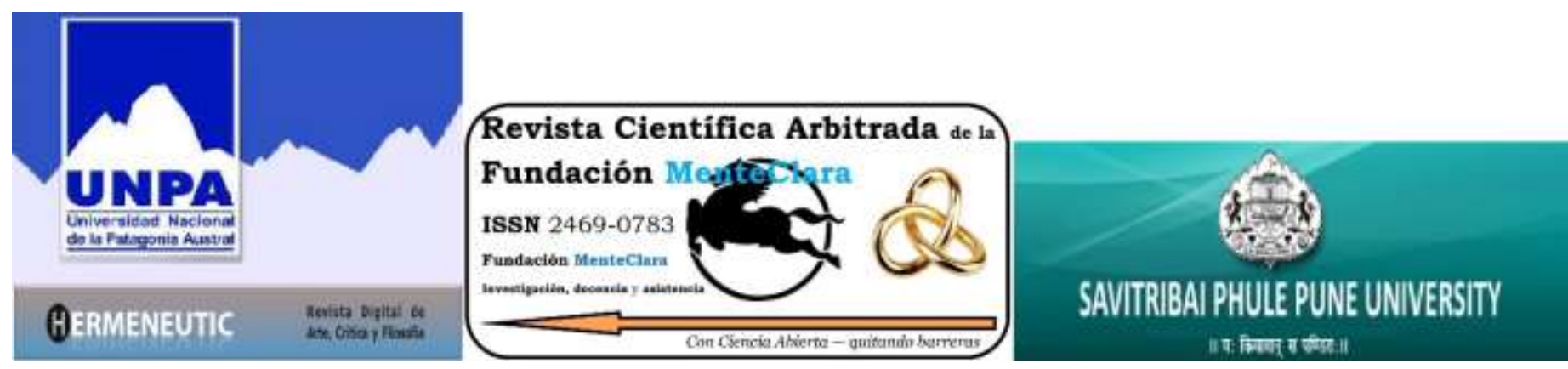

\title{
Convocatoria de autores para número monográfico: Filosofías igualitarias de castas, clase, género y opciones de vida
}

El departamento de Hermenéutica Aplicada de la Universidad Nacional de la Patagonia Austral (Argentina), la Revista Científica Arbitrada de la Fundación MenteClara Internacional (RCAFMC) y el departamento de Historia de la Universidad Savitribai Phule Pune (India) convocan a la presentación de trabajos de investigación enfocados en:

\section{Filosofías igualitarias de castas, clase, género y opciones de vida}

Que busquen las relaciones entre las filosofías humanistas, la fenomenología existencial y su influencia en el pensamiento y la obra de quienes propiciaron la evolución de los sudras y dalits de la India por encima de la condición de ignorancia y esclavitud, tal como lo hicieron el Dr. Bhimrao Ambedkar, Savitribai Phule, Sathyavani Muthu y otros en otros continentes.

Esta convocatoria tiene como objeto debatir, articular conceptos y producir nuevas herramientas académicas para emancipar a las personas y elevar a todos a la misma condición de ser, reuniendo en un foro común a diferentes disciplinas que contribuyan a visibilizar y solucionar desigualdades de casta, clase, género y opciones de vida.

El número monográfico será publicado en la RCAFMC el 30 de abril de 2020 con introducción y conclusiones a cargo de Aldo Enrici y Oscar R. Gómez. El pre-print de los artículos presentados serán publicados inmediatamente de ser aceptados para su evaluación con su DOI correspondiente para permitir el libre debate entre los autores participantes y colaboradores externos. La recepción de trabajos cierra el 30 de marzo de 2020.

Todos los artículos deberán ser presentados siguiendo estrictamente las normas editoriales expresadas en https://fundacionmenteclara.org.ar/revista/index.php/RCA/about/submissions\#authorGuidelines

Los artículos recibidos, en español o en inglés, serán analizados primero por los comités editoriales de Hermeneutic, de la RCAFMC y el Departamento de Historia de la Universidad Savitribai Phule Pune teniendo en cuenta la originalidad de la investigación, su contribución al estado actual del conocimiento, la experiencia del autor en su campo de estudio, la claridad y precisión de la contribución presentada, así como su ajuste a las líneas del monográfico.

Si el artículo no cumpliera los requisitos para este monográfico, pero fuera original y cumpliera las normas para envío de artículos, será devuelto al autor con la invitación a publicar en los números ordinarios de Hermeneutic o RCAFMC.

Si cumplen los criterios para incluirse en este número monográfico se enviarán al proceso de revisión doble ciego siendo uno de los revisores seleccionados por el comité científico de la UNAP y el otro, por el comité científico de la FMC. El proceso de revisión se ajustará a lo establecido en https://fundacionmenteclara.org.ar/revista/index.php/RCA/about/editorialPolicies\#peerReviewProcess

Los cargos de procesamiento editorial serán íntegramente financiados por la UNAP y la FMC, tal como se señala para el resto de los artículos en las normas para autores, no debiendo el investigador abonar ningún importe por ningún concepto.

Para la presentación de artículos se recomienda la lectura de los siguientes artículos publicados en esta revista coincidentes con la temática de la presente convocatoria: 


\section{Bibliografía}

Acri, A. (2017). VIAJANDO POR LOS «CAMINOS DEL SUR»: EL BUDISMO ESOTÉRICO EN EL ASIA MARÍTIMA, SIGLOS VIIXIII D.C.. Revista Científica Arbitrada de la Fundación MenteClara, 2(2), 6-62. doi:https://doi.org/10.32351/rca.v2.2.28

Basu, R. (2017). BASES PSÍQUICAS DE LA EXPLOTACIÓN DE LOS DALITS EN LA INDIA. Revista Científica Arbitrada de la Fundación MenteClara, 2(1), 8-74. doi:https://doi.org/10.32351/rca.v2.1.25

Basu, R. (2018). De la revolución cultural a la evolución cultural. Revista Científica Arbitrada de la Fundación MenteClara, 3(1), 7-28. doi:https://doi.org/10.32351/rca.v3.1.37

García, R. (2016). LAS REFORMAS RELIGIOSAS DE AKBAR Y SU RELIGIÓN PERSONAL. Revista Científica Arbitrada de la Fundación MenteClara, 1(3), 8-23. doi:https://doi.org/10.32351/rca.v1.3.20

Gómez, O. (2016). ANTONIO DE MONTSERRAT - LA RUTA DE LA SEDA Y LOS CAMINOS SECRETOS DEL TANTRA. Revista Científica Arbitrada de la Fundación MenteClara, 1(1), 5-20. doi:https://doi.org/10.32351/rca.v1.1.8

Gómez, O. (2017). ANÁLISIS CRÍTICO DEL KULARNAVA TANTRA -PARTE 1- UN PRÓLOGO VICIADO DE SEXUALIDAD REPRIMIDA. Revista Científica Arbitrada de la Fundación MenteClara, 2(1), 114-141. doi:https://doi.org/10.32351/rca.v2.1.26

Gómez, O. (2017). TANTRA O YOGA. ESTUDIOS CLÍNICOS, 3a PARTE: COMPARATIVA. Revista Científica Arbitrada de la Fundación MenteClara, 2(2), 117-142. doi:https://doi.org/10.32351/rca.v2.2.32

Kumbhojkar, S. (2018). Dalits, internet y políticas emancipadoras. Revista Científica Arbitrada de la Fundación MenteClara, 3(1), 45-56. doi:https://doi.org/10.32351/rca.v3.1.42

Kumbhojkar, S., Magar, R., \& Ozarkar, S. (2019). ¿Acceso denegado? : Capital cultural y acceso digital. Revista Científica Arbitrada de la Fundación MenteClara, 4(1), 65-78. doi:https://doi.org/10.32351/rca.v4.1.70 